\title{
Análise de dados do Sistema de Informação de Vigilância da Qualidade da Água para Consumo Humano (Sisagua) no estado do Amazonas, 2016-2020
}

\author{
Data analysis of the Water Quality Surveillance Information System \\ for Human Consumption (Sisagua) in the state of Amazonas, \\ 2016-2020
}

André Bento Chaves Santana* ${ }^{\text {ID }}$

Amanda Forster Lopes

Abinadabis Parentes Mendes

Klenicy Kazumy de Lima

Yamaguchi
Instituto de Saúde e Biotecnologia (ISB), Universidade Federal do Amazonas (UFAM), Coari, AM, Brasil

\section{* E-mail: ibentoi@gmail.com}

Recebido: 05 maio 2021 Aprovado: 19 out 2021

\section{RESUMO}

Introdução: Avaliar os parâmetros de qualidade da água é fundamental para a vigilância em saúde pública e o direcionamento de ações de prevenção de doenças no âmbito populacional. Objetivo: Realizar a análise dos dados de vigilância de parâmetros químicos, físicos e microbiológicos para avaliação da qualidade da água de consumo humano no estado do Amazonas, com base no Sistema de Informação de Vigilância da Qualidade da Água para Consumo Humano (Sisagua). Método: Estudo exploratório-descritivo baseado em pesquisa quantitativa para a análise da vigilância da qualidade da água de consumo humano e de parâmetros químicos, físicos e microbiológicos nas amostras de água no estado do Amazonas, no período de 2016 a 2020. Testes estatísticos não paramétricos foram realizados para comparar diferenças na proporção de cada categoria e adequação de acordo com a microrregião geográfica. Resultados: As microrregiões do interior apresentam menor proporção de municípios com registro de informações sobre a qualidade da água. As amostras da microrregião da capital apresentaram menor teor de cloro residual livre, maior concentração de fluoreto, e valores superiores para coloração aparente e turbidez. As análises de tendências evidenciaram melhorias nos parâmetros para cor aparente em amostras obtidas na microrregião de capital e, para cloro residual livre, coliformes totais e Escherichia coli em amostras de água coletadas no interior. Conclusões: Houve diferenças no percentual de inadequações dos parâmetros das amostras avaliadas de acordo com a localidade. Ressalta-se a necessidade de melhorias na gestão da vigilância da qualidade da água, no que se refere ao olhar atento para as ações de análise e fiscalização no estado do Amazonas.

PALAVRAS-CHAVE: Água; Abastecimento de Água; Saneamento Básico; Vigilância em Saúde Pública; Política Pública; Sistemas de Informação

\section{ABSTRACT}

Introduction: The evaluation of water quality parameters is fundamental for public health and disease prevention in the population. Objective: To perform an analysis of surveillance data of chemical, physical, and microbiological parameters to evaluate the quality of water for human consumption in the State of Amazonas, based on the Information System of Water Quality Surveillance for Human Consumption (Sisagua). Method: An exploratory-descriptive study based on quantitative research was carried out to analyze the quality of human consumption water and chemical, physical, and microbiological parameters, measured in water samples in the State of Amazonas, from 2016 to 2020. Nonparametric statistical tests were performed to compare differences in the proportion of each category and adequacy according to the geographic microregion. Results: Inland micro-regions have a lower proportion of municipalities with data recording of water quality parameters. The water samples from the microregion of the capital presented 
lower free residual chlorine content, higher fluoride concentration, and higher values for apparent color and turbidity. Trend analyses showed improvements in parameters for apparent color in samples obtained in the capital microregion and, for free residual chlorine, total coliforms and Escherichia coli in water samples collected in the interior of Amazonas. Conclusions: There were differences in the profile of chemical, physical, and microbiological parameters of the samples evaluated according to the locality. The need for improvements in the management of water quality surveillance is emphasized, especially related to looking carefully at the actions of analysis and supervision in the State of Amazonas.

KEYWORDS: Water; Water Supply; Basic Sanitation; Public Health Surveillance; Public Policy; Information Systems

\section{INTRODUÇÃO}

Manter a segurança e a qualidade da água de consumo humano, visando a garantia do direito ao acesso a um produto com índices aceitáveis de substâncias químicas e microbiológicas, é um desígnio imprescindível para proporcionar qualidade de vida à população brasileira e reduzir a mortalidade e a incidência de patologias associadas à contaminação da água ${ }^{1,2,3}$.

Para regulamentar esses índices a nível nacional, tem-se o Anexo XX da Portaria de Consolidação ${ }^{\circ}$ 5, de 28 de setembro de 2017, do Ministério da Saúde, que estabelece os dados sobre a potabilidade e os procedimentos de controle e vigilância da água para consumo humano, bem como as competências e a responsabilidade das autoridades públicas. Segundo essa legislação, os critérios e os parâmetros para a qualidade da água de consumo devem apresentar ausência de microrganismos patogênicos, índices aceitáveis de substâncias químicas inorgânicas e orgânicas e conter parâmetros físicos de cor aparente, turbidez e acidez previamente estabelecidos ${ }^{4}$.

Patologias de veiculação hídrica vêm ocasionando uma série de transtornos epidemiológicos e sociais que podem estar diretamente relacionadas a condições higiênico-sanitárias e de saneamento básico precárias, possível reflexo da ausência do cumprimento de políticas públicas, limitado o conhecimento e a fiscalização sobre os cuidados com o descarte inadequado de substâncias contaminantes e dejetos sólidos no meio ambiente, cenário comum em países em desenvolvimento como o Brasil $5,6,7,8$.

Inadequações dos parâmetros de potabilidade na água de consumo constituem um risco à saúde da população, além de refletir problemas ambientais, ausência de abordagens tecnológicas apropriadas para os sistemas de abastecimento e falta de políticas públicas atuantes. Entre os riscos, tem-se a contaminação microbiológica que pode ocasionar parasitoses, doença diarreica aguda (DDA) e hepatites ${ }^{3}$.

No Amazonas, a maioria das cidades é rodeada por rios, tendo nesse recurso natural a fonte de sobrevivência e consumo das populações. No entanto, pesquisas vêm demonstrando que nem sempre esse recurso hídrico disponibilizado para a população é adequado para o consumo, sendo diagnosticada a presença de níveis microbiológicos, químicos e físico-químicos fora do preconizado pelos órgãos regulamentadores ${ }^{9,10,11}$.

Propostas de vigilância de indicadores estão ocorrendo, analisando os impactos antropogênicos para a qualidade da água e fazendo alertas sobre as consequências a médio e longo prazo da falta de cuidado com esse recurso natural ${ }^{12,13,14}$.

No âmbito das políticas públicas de saúde, existe uma confluência de órgãos, políticas públicas, agendas e atos normativos que estabelecem uma rede de ações e serviços para assegurar o monitoramento do abastecimento, qualidade e regulação da água para consumo humano no Brasil. O Programa Nacional de Vigilância em Saúde Ambiental Relacionada à Qualidade da Água para Consumo Humano (Vigiagua) segue as diretrizes e princípios norteadores do Sistema Único de Saúde (SUS) e se articula com o Sistema Nacional de Vigilância Ambiental em Saúde (Sinvas), para as ações e serviços, públicos e privados, direcionados para o monitoramento da água para consumo humano ${ }^{15,16}$.

O Sistema de Informação de Vigilância da Qualidade da Água para Consumo Humano (Sisagua) integra a Vigilância Ambiental em Saúde, sendo o sistema informatizado que possibilita que os gestores regionais façam o acompanhamento dos dados sobre a qualidade da água, incluindo o perfil das áreas abastecidas por concessionárias. A organização deste sistema possibilita a tomada de decisão para medidas corretivas e preventivas, sempre que são percebidas alterações nos parâmetros avaliados para indicar as áreas com maiores riscos de comprometimento da qualidade da água ${ }^{3,17}$.

Os dados do Sisagua são obtidos de forma rotineira por profissionais do setor da saúde atuantes na vigilância e por gestores responsáveis pelos serviços de abastecimento de água e controle de qualidade. Desta forma, o Sisagua contribui para o gerenciamento dos riscos que as contaminações hídricas podem ocasionar por meio do acesso a informações dos laudos microbiológicos, químicos e físico-químicos da potabilidade da água em todo o território nacional ${ }^{17}$.

Com base no contexto apresentado, o diagnóstico sobre os parâmetros químicos, físicos e microbiológicos da qualidade da água poderão contribuir para o planejamento de ações de monitoramento e de prevalência e controle de patologias que tenham relação com contaminações hídricas, para que se possa ter um olhar mais abrangente sobre a situação da água de consumo nas cidades do Amazonas.

O objetivo deste artigo foi analisar dados de parâmetros químicos, físicos e microbiológicos registrados no Sisagua para avaliação da qualidade da água para consumo humano distribuída no estado do Amazonas, comparando a microrregião da capital em relação às demais microrregiões situadas em localidades do interior. 


\section{MÉTODO}

\section{Desenho do estudo}

Foi realizado um estudo exploratório-descritivo baseado em pesquisa quantitativa para análise de parâmetros químicos, físicos e microbiológicos de amostras da água distribuída para o consumo humano no estado do Amazonas.

\section{Descrição geral da localidade}

0 estado do Amazonas é formado por 62 municípios pertencentes a 13 microrregiões (Rio Negro, Japurá, Alto Solimões, Juruá, Tefé, Coari, Manaus, Rio Preto da Eva, Itacoatiara, Parintins, Boca do Acre, Purus e Madeira), com população estimada de 4.207.714 habitantes ${ }^{18}$. A microrregião de Manaus contempla sete municípios: Autazes, Careiro, Careiro da Várzea, Iranduba, Manacapuru, Manaquiri e Manaus. Os demais municípios integram as microrregiões que abrangem localidades no interior do estado ${ }^{19}$.

\section{Base de dados}

Foram utilizados bancos de dados públicos de livre acesso do Sisagua disponibilizados pelo Ministério da Saúde, contemplando o período de 2016 a 2020. O conjunto de dados e o dicionário de variáveis do Sisagua foram obtidos por meio da consulta e busca no Portal Brasileiro de Dados Abertos (disponível em https: / /dados.gov.br/dataset?tags=SISAGUA - acessos realizados em 12/02/2021 e 13/02/2021). Foram contemplados dados de 181.198 amostras oriundas do Sistema de Abastecimento de Água - SAA $(68,24 \%)$ ou procedentes da Solução Alternativa Coletiva SAC (31,76\%). Não foram incluídos dados de amostras obtidas da Solução Alternativa Individual (SAl), devido à ausência de controle efetuado pelo Sisagua ${ }^{20}$. Ademais, as amostras vindas de SAl representaram apenas 2,34\% das amostras, constatando-se número de dados faltantes acima de $70 \%$ para os parâmetros de interesse do estudo, incluindo a ausência de dados para cloro residual livre, fluoreto, cor aparente e $\mathrm{pH}$.

\section{Parâmetros químicos, físicos e microbiológicos}

Foram selecionados para a análise os parâmetros básicos de qualidade da água contemplados no Anexo XX da Portaria de Consolidação $n^{\circ} 5 / 2017^{4}$, referentes a: a) Cloro residual livre ( $\left.\mathrm{mg} / \mathrm{L}\right)$; b) Cor aparente (uH); c) Fluoreto (mg/L); d) Turbidez (uT); e) $\mathrm{pH}$; f) Bactérias heterotróficas (UFC/mL); g) Coliformes totais; h) Escherichia coli.

As mensurações envolvendo variáveis contínuas sobre os parâmetros químicos, físicos e microbiológicos foram classificadas de acordo com os valores das medianas dos parâmetros avaliados seguindo as normas do Anexo XX da Portaria de Consolidação $n^{\circ} 5 / 2017^{4}$.

A classificação do teor de cloro residual livre foi realizada em três categorias: (i) abaixo do recomendado, com valores inferiores a $0,2 \mathrm{mg} / \mathrm{L}$; (ii) faixa ideal recomendada com valores entre $0,2 \mathrm{mg} / \mathrm{L}$ e $5 \mathrm{mg} / \mathrm{L}$; (iii) acima do recomendado, com valores superiores a $5 \mathrm{mg} / \mathrm{L}$.
Em relação ao teor de fluoreto, foram consideradas as seguintes classificações: (i) abaixo do recomendado, para valores inferiores a $0,6 \mathrm{mg} / \mathrm{L}$; (ii) faixa ideal recomendada, correspondendo a valores entre $0,6 \mathrm{mg} / \mathrm{L}$ e $1,5 \mathrm{mg} / \mathrm{L}$; (iii) acima do recomendado, considerando os valores acima de $1,5 \mathrm{mg} / \mathrm{L}$.

Nas classificações de potabilidade da água para cor aparente e turbidez foram classificadas nas faixas ideais recomendadas as amostras com valor máximo permitido de 15 uH e 5 uT, respectivamente.

Para a faixa de $\mathrm{pH}$ das amostras, foi realizada a divisão em três categorias: (i) abaixo do recomendado, com valores inferiores a 6,0; (ii) na faixa ideal recomendada, para valores entre 6,0 e 9,5; (iii) acima do recomendado, para valores superiores a 9,5.

Para coliformes totais e $E$. coli, foram analisados os percentuais de amostras com ausência destes micro-organismos nas amostras coletadas, considerando a tolerância de ausência em $100 \mathrm{~mL}$ em 95\% das amostras examinadas no mês ${ }^{4}$.

\section{Análises estatísticas}

Os dados dos parâmetros químicos e físicos não apresentam distribuição normal, conforme verificado pela aplicação de testes de Shapiro-Wilk. Portanto, para mensurar a diferença entre as medianas dos parâmetros foram aplicados testes de Mann-Whitney, de modo a avaliar possíveis diferenças entre as amostras analisadas de acordo com a microrregião geográfica.

O modelo de regressão linear generalizada de Prais-Winsten foi utilizado para avaliação das tendências de variação temporal para os percentuais das classificações dos parâmetros químicos, físicos e microbiológicos. De forma complementar, foi aplicado o teste de Durbin-Watson para verificar a autocorrelação serial de percentuais de cada parâmetro analisado. A aplicação deste modelo de regressão é fundamental para evitar que variações pouco expressivas sejam erroneamente apontadas como significantes, com aplicação na análise de qualidade da água ${ }^{21}$. No delineamento dos modelos de regressão, as classificações dos parâmetros químicos, físicos e microbiológicos foram definidos como variáveis dependentes, enquanto o ano de registro foi definido como a variável independente.

Considerando tais pressupostos, calculou-se a variação percentual anual para a estimativa quantitativa tendência e determinação do intervalo de confiança de 95\% (IC95\%), considerando os coeficientes $b$ mínimo e $b$ máximo, utilizando-se respectivamente as equações:

$$
\begin{gathered}
\text { VPA }=\left[-1+\mathrm{e}^{\mathrm{b}}\right] * 100 \% \\
\mathrm{IC} 95 \%=\left[-1+10^{\mathrm{b} \text { mínimo }}\right] * 100 \%\left[-1+10^{\mathrm{b} \text { máximo }}\right] * 100 \%
\end{gathered}
$$

Onde: (VPA) Variação percentual anual; (b) coeficiente beta estimado por regressão de Prais-Winsten para inferência da variação percentual anual.

Os resultados das análises estatísticas foram avaliados com base no critério de nível de probabilidade de significância menor ou 
igual a $5 \%(\mathrm{p} \leq 0,05)$. Todas as análises estatísticas e as projeções georreferenciadas utilizando o shape file, disponibilizadas pelo Instituto Brasileiro de Geografia e Estatística (IBGE), foram realizadas no programa Stata, versão 15.1 (StataCorp - College Station, Texas, USA).

\section{Aspectos éticos}

De acordo com a legislação brasileira, pesquisas que utilizem dados secundários de domínio público sem a possibilidade de identificação individual não serão avaliadas pelo sistema Comitê de Ética em Pesquisa/Comissão Nacional de Ética em Pesquisa (CEP/Conep), conforme a Resolução $\mathrm{n}^{\circ} 510$, de 7 de abril de
2016, publicada pelo Conselho Nacional de Saúde. Desta forma, não se aplica o critério de aprovação junto ao CEP para execução desta pesquisa.

\section{RESULTADOS}

Foi possível verificar que todos os municípios da microrregião de Manaus apresentavam dados registrados para vigilância de parâmetros básicos de qualidade da água (Tabela 1 e Figura). Em contrapartida, apenas 30 municípios (54,56\%) das microrregiões do interior apresentaram dados registrados no Sisagua (Tabela 1 e Figura).

Tabela 1. Distribuição dos municípios com dados de vigilância de parâmetros básicos de qualidade da água cadastrados no Sisagua. Amazonas, $2016-2020$.

\begin{tabular}{lccccccc}
\hline \multirow{2}{*}{ Variável } & \multicolumn{3}{c}{ Amazonas } & & \multicolumn{2}{c}{ Microrregião geográfica de Manaus } & Microrregiões do interior \\
\cline { 2 - 7 } & Total & $\%$ & Total & $\%$ & Total \\
\hline Municípios cadastrados & 37 & 59,68 & 7 & 100,00 & 30 & 54,56 \\
\hline
\end{tabular}

Fonte: Elaborada pelos autores, 2021.

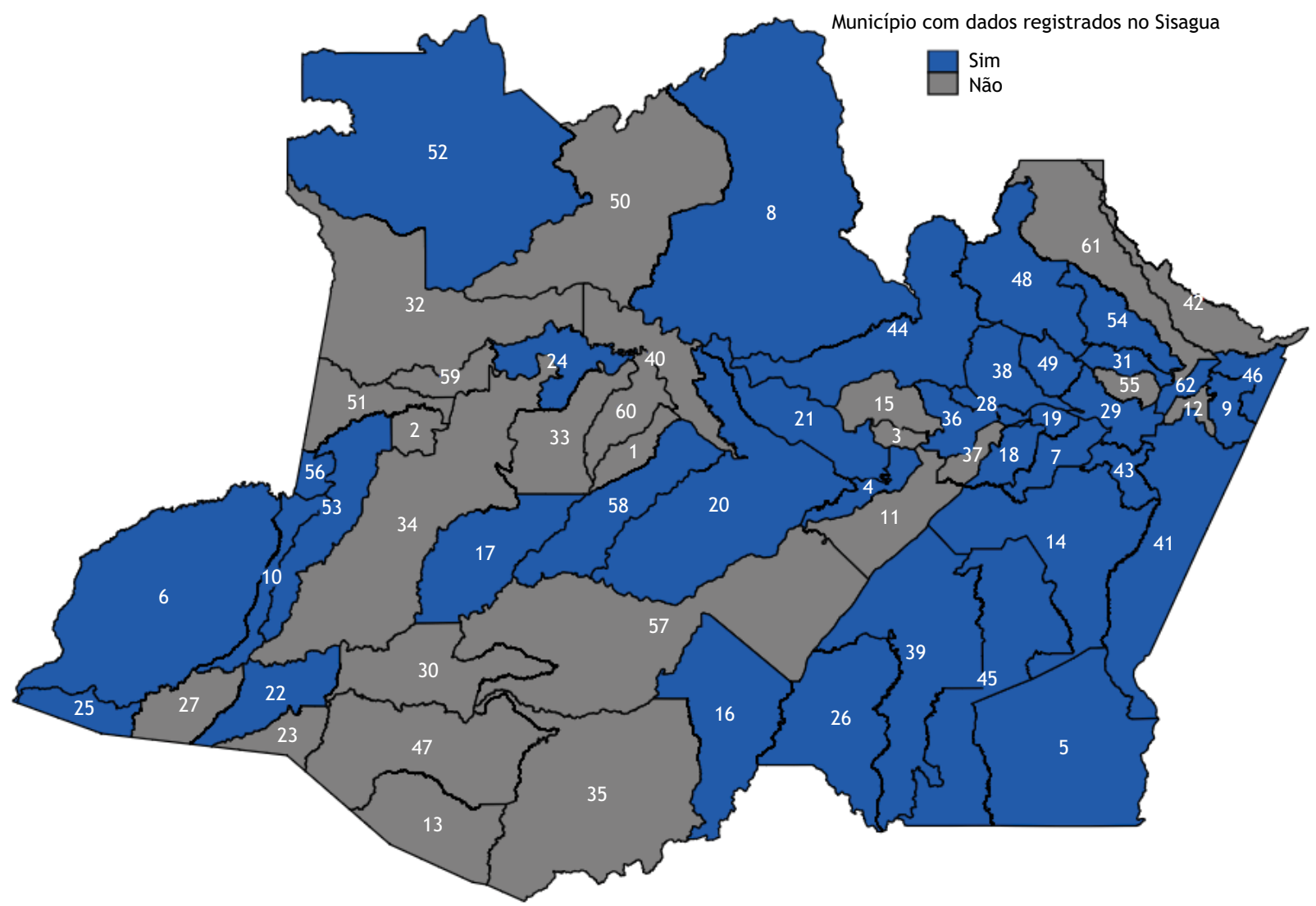

Fonte: Elaborada pelos autores, 2021.

1: Alvarães; 2: Amaturá; 3: Anamã; 4: Anori; 5: Apuí; 6: Atalaia do Norte; 7: Autazes; 8: Barcelos; 9: Barreirinha; 10: Benjamin Constant; 11: Beruri; 12: Boa Vista do Ramos; 13: Boca do Acre; 14: Borba; 15: Caapiranga; 16: Canutama; 17: Carauari; 18: Careiro; 19: Careiro da Várzea; 20: Coari; 21: Codajás; 22: Eirunepé; 23: Envira; 24: Fonte Boa; 25: Guajará; 26: Humuaitá; 27: Ipixuna; 28: Iranduba; 29: Itacoatiara; 30: Itamarati; 31: Itapiranga; 32: Japurá; 33: Juruá; 34: Jutaí; 35: Lábrea; 36: Manacapuru; 37: Manaquiri; 38: Manaus; 39: Manicoré; 40: Maraã; 41: Maués; 42: Nhamundá; 43: Nova Olinda do Norte; 44: Novo Airão; 45: Novo Aripuanã; 46: Parintins; 47: Pauini; 48: Presidente Figueiredo; 49: Rio Preto da Eva; 50: Santa Isabel do Rio Negro; 51: Santo Antônio do Içá; 52: São Gabriel da Cachoeira; 53: São Paulo de Olivença; 54: São Sebastião do Uatumã; 55: Silves; 56: Tabatinga; 57: Tapauá; 58: Tefé; 59: Tonantins; 60: Uarini; 61: Urucará; 62: Urucurituba.

Figura. Distribuição dos municípios com dados registrados para vigilância de parâmetros básicos do Sisagua. Amazonas, 2016-2020. 
Na Tabela 2 são apresentadas as quantificações dos parâmetros químicos e físicos das amostras de água coletadas no Amazonas, incluindo análises estratificadas por microrregiões. De modo geral, as amostras de água coletadas na microrregião de Manaus apresentam menor concentração de cloro residual livre, maior concentração de fluoreto, maior intensidade de coloração aparente e maior turbidez em comparação com amostras obtidas nas microrregiões do interior.

Na Tabela 3 são apresentadas as tendências dos percentuais referentes à classificação dos parâmetros químicos, físicos e microbiológicos de amostras de água coletadas na microrregião de Manaus. Verificam-se oscilações dos parâmetros para cloro residual livre, fluoreto, $\mathrm{pH}$, ausência de coliformes totais e $E$. coli. Observa-se, em 2020, a alta proporção de amostras com teor de cloro residual livre abaixo dos valores recomendados. Neste mesmo ano, foi verificado que todas as amostras analisadas apresentaram valores para as concentrações de fluoreto abaixo do recomendado. Ressalta-se que, no período analisado, a maior parte das amostras apresentaram valores de $\mathrm{pH}$ abaixo do recomendado. Verificou-se ainda a tendência de aumento na proporção de amostras dentro da faixa recomendada para cor aparente.

Tabela 2. Quantificação dos parâmetros químicos e físicos de qualidade da água distribuída à população. Amazonas, $2016-2020$.

\begin{tabular}{|c|c|c|c|c|c|c|c|c|c|c|}
\hline \multirow{2}{*}{ Parâmetro } & \multicolumn{3}{|c|}{ Amazonas } & \multicolumn{3}{|c|}{ Microrregião de Manaus } & \multicolumn{3}{|c|}{ Demais microrregiões } & \multirow{2}{*}{$\begin{array}{l}\text { Valor } \\
\text { de } p\end{array}$} \\
\hline & $\mathbf{N}$ & Med & IQ & $\mathbf{N}$ & Med & IQ & $\mathbf{N}$ & Med & IQ & \\
\hline $\begin{array}{l}\text { Cloro residual livre } \\
\text { (mg/L) }\end{array}$ & 20.148 & 0,20 & $(0,00 ; 0,40)$ & 12.377 & 0,10 & $(0,00 ; 0,27)$ & 7.771 & 0,20 & $(0,04 ; 0,6)$ & $<0,001^{*}$ \\
\hline Fluoreto (mg/L) & 5.508 & 0,72 & $(0,37 ; 0,88)$ & 5.378 & 0,73 & $(0,44 ; 0,89)$ & 130 & 0,00 & $(0,00 ; 0,00)$ & $<0,001^{*}$ \\
\hline Cor aparente $(\mathrm{uH})$ & 15.991 & 2,40 & $(0,20 ; 5,10)$ & 10.892 & 2,90 & $(1,40 ; 5,60)$ & 5.099 & 0,00 & $(0,00 ; 5,00)$ & $<0,001^{*}$ \\
\hline Turbidez (uT) & 33.032 & 0,79 & $(0,18 ; 1,60)$ & 16.595 & 0,85 & $(0,30 ; 1,40)$ & 16.467 & 0,66 & $(0,10 ; 2,08)$ & $<0,001^{*}$ \\
\hline $\mathrm{pH}$ & 24.783 & 5,78 & $(5,13 ; 6,30)$ & 13.635 & 5,60 & $(5,10 ; 5,92)$ & 11.148 & 6,22 & $(5,20 ; 6,85)$ & $<0,001^{*}$ \\
\hline
\end{tabular}

Fonte: Elaborada pelos autores, 2021.

N: Número de amostras; Med: Mediana; IQ: Intervalo interquartil: Percentil 25; Percentil 75.

$\left(^{*}\right)$ Aplicação do teste de Mann-Whitney para comparação entre medianas dos parâmetros avaliados na microrregião de Manaus e demais microrregiões.

Tabela 3. Análise de tendência dos percentuais para classificações dos parâmetros químicos, físicos e microbiológicos conforme padrão de potabilidade da água distribuída na microrregião de Manaus. Amazonas, 2016-2020.

\begin{tabular}{|c|c|c|c|c|c|c|c|c|}
\hline \multirow{2}{*}{ Parâmetro } & \multicolumn{5}{|c|}{ Amostras (\%) } & \multirow{2}{*}{ Variação anual (\%) } & \multirow{2}{*}{ Valor de $p$} & \multirow{2}{*}{ Tendência } \\
\hline & 2016 & 2017 & 2018 & 2019 & 2020 & & & \\
\hline \multicolumn{9}{|l|}{ Cloro residual livre } \\
\hline Abaixo do recomendado & 60,31 & 34,40 & 10,06 & 72,12 & 66,06 & $5,40(-13,90 ; 24,71)$ & 0,44 & Oscilação \\
\hline Faixa recomendada & 39,69 & 65,60 & 89,94 & 27,88 & 33,91 & $-5,73(-24,80 ; 13,35)$ & 0,41 & Oscilação \\
\hline Acima do recomendado & 0,00 & 0,00 & 0,00 & 0,00 & 0,04 & $0,01(-0,00 ; 0,02)$ & 0,14 & Oscilação \\
\hline \multicolumn{9}{|l|}{ Fluoreto } \\
\hline Abaixo do recomendado & 38,14 & 20,97 & 18,82 & 38,11 & 100,00 & $13,97(-16,31 ; 44,25)$ & 0,24 & Oscilação \\
\hline Faixa ideal & 61,86 & 78,75 & 60,97 & 0,00 & 0,00 & $-13,99(-42,87 ; 14,90)$ & 0,22 & Oscilação \\
\hline Acima do recomendado & 0,00 & 0,28 & 2,50 & 0,93 & 0,00 & $0,07(-0,83 ; 0,97)$ & 0,81 & Oscilação \\
\hline \multicolumn{9}{|l|}{ Cor aparente } \\
\hline Faixa ideal & 94,49 & 94,78 & 93,77 & 98,36 & 98,81 & $1,27(0,43 ; 2,12)$ & 0,02 & Aumento \\
\hline \multicolumn{9}{|l|}{ Turbidez } \\
\hline Faixa ideal & 98,79 & 99,04 & 97,87 & 98,64 & 99,23 & $0,03(-0,41 ; 0,47)$ & 0,85 & Oscilação \\
\hline \multicolumn{9}{|l|}{$\mathrm{pH}$} \\
\hline Abaixo do recomendado & 63,88 & 84,91 & 72,71 & 83,22 & 78,71 & $2,08(-0,26 ; 4,40)$ & 0,07 & Oscilação \\
\hline Faixa ideal & 36,01 & 15,09 & 27,29 & 16,78 & 21,29 & $-2,05(-4,36 ; 0,25)$ & 0,07 & Oscilação \\
\hline Acima do recomendado & 0,11 & 0,00 & 0,00 & 0,00 & 0,00 & $-0,02(-0,06 ; 0,02)$ & 0,19 & Oscilação \\
\hline \multicolumn{9}{|l|}{ Coliformes totais } \\
\hline Ausência & 82,88 & 83,86 & 77,88 & 82,59 & 89,54 & $1,16(-2,46 ; 4,77)$ & 0,38 & Oscilação \\
\hline \multicolumn{9}{|l|}{ E. coli } \\
\hline Ausência & 93,13 & 96,77 & 95,90 & 97,27 & 96,89 & $0,21(-0,04 ; 0,47)$ & 0,08 & Oscilação \\
\hline
\end{tabular}

Fonte: Elaborada pelos autores, 2021. 
Tabela 4. Análise de tendência dos percentuais para classificações dos parâmetros químicos, físicos e microbiológicos conforme padrão de potabilidade da água distribuída no interior do estado. Amazonas, 2016-2020.

\begin{tabular}{|c|c|c|c|c|c|c|c|c|}
\hline \multirow{2}{*}{ Parâmetro } & \multicolumn{5}{|c|}{ Amostras (\%) } & \multirow{2}{*}{ Variação anual (\%) } & \multirow{2}{*}{ Valor de $p$} & \multirow{2}{*}{ Tendência } \\
\hline & 2016 & 2017 & 2018 & 2019 & 2020 & & & \\
\hline \multicolumn{9}{|l|}{ Cloro residual livre } \\
\hline Abaixo do recomendado & 41,64 & 65,22 & 45,69 & 36,15 & 19,86 & $-8,81(-20,39 ; 2,77)$ & 0,09 & Oscilação \\
\hline Faixa recomendada & 58,08 & 34,66 & 54,16 & 63,77 & 80,14 & $8,17(-2,50 ; 18,85)$ & 0,09 & Oscilação \\
\hline Acima do recomendado & 0,28 & 0,11 & 0,16 & 0,08 & 0,00 & $-0,05(-0,08 ;-0,03)$ & 0,01 & Queda \\
\hline \multicolumn{9}{|l|}{ Fluoreto } \\
\hline Abaixo do recomendado & - & 50,00 & 100,00 & 100,00 & 66,67 & $18,20(-18,67 ; 55,07)$ & 0,21 & Oscilação \\
\hline Faixa recomendada & - & 25,00 & 0,00 & 0,00 & 0,00 & $-4,60(-13,15 ; 3,95)$ & 0,19 & Oscilação \\
\hline Acima do recomendado & - & 25,00 & 0,00 & 0,00 & 33,33 & $1,52(-15,92 ; 18,96)$ & 0,80 & Oscilação \\
\hline \multicolumn{9}{|l|}{ Cor aparente } \\
\hline Faixa recomendada & 100,00 & 98,79 & 97,41 & 91,23 & 98,05 & $-2,12(-2,76 ;-1,47)$ & 0,005 & Queda \\
\hline \multicolumn{9}{|l|}{ Turbidez } \\
\hline Faixa recomendada & 97,85 & 90,08 & 91,71 & 89,70 & 95,13 & $-0,52(-3,23 ; 2,19)$ & 0,58 & Oscilação \\
\hline \multicolumn{9}{|l|}{$\mathrm{pH}$} \\
\hline Abaixo do recomendado & 25,62 & 52,13 & 19,21 & 49,17 & 31,53 & $0,35(-4,26 ; 4,95)$ & 0,83 & Oscilação \\
\hline Faixa recomendada & 74,38 & 47,87 & 80,61 & 50,80 & 68,42 & $-0,36(-4,90 ; 4,18)$ & 0,82 & Oscilação \\
\hline Acima do recomendado & 0,00 & 0,00 & 0,18 & 0,03 & 0,05 & $0,01(-0,04 ; 0,06)$ & 0,46 & Oscilação \\
\hline \multicolumn{9}{|l|}{ Coliformes totais } \\
\hline Ausência & 61,12 & 65,99 & 67,43 & 77,19 & 81,60 & $5,26(4,11 ; 6,40)$ & 0,001 & Aumento \\
\hline \multicolumn{9}{|l|}{ E. coli } \\
\hline Ausência & 93,52 & 94,02 & 94,31 & 94,90 & 94,73 & $0,40(0,35 ; 0,44)$ & 0,001 & Aumento \\
\hline
\end{tabular}

Fonte: Elaborada pelos autores, 2021.

Os resultados mostrados na Tabela 4 demonstram oscilações nas proporções de amostras segundo classificação dos parâmetros para fluoreto, turbidez e pH de amostras de água coletadas no interior do estado do Amazonas. Em tais localidades foi possível observar tendência de queda nas proporções de amostras com concentração de cloro residual livre acima do recomendado e tendência de queda na proporção de amostras na faixa recomendada para cor aparente. Considerando o período de 2016 a 2020, todas as amostras analisadas apresentaram concentração de fluoreto acima ou abaixo do recomendado. Todavia, foi possível observar uma tendência de aumento nas proporções de amostras com ausência de coliformes totais e $E$. coli.

\section{DISCUSSÃO}

Este estudo avaliou os dados de vigilância de parâmetros básicos do Sisagua no estado do Amazonas, mostrando diferenças entre a microrregião de Manaus em relação às demais regiões, no que se refere ao número de municípios cadastrados e para as aferições de qualidade para os padrões químicos, físicos e microbiológicos de potabilidade da água.

A baixa proporção de municípios do interior do estado com informações no Sisagua em relação à microrregião geográfica de Manaus evidencia aspectos já discutidos previamente na literatura, como entraves técnico-operacionais para a gestão eficiente do Vigiagua, possivelmente motivadas por falhas no cadastramento das diversas formas de abastecimento de água e na vigilância às instalações de abastecimento, baixo número de coletas de amostras, deficiências nas análises de dados e de instrumentos para georreferenciamento ${ }^{15}$. Mais especificamente quanto ao Amazonas, os resultados sugerem a predominância da concentração dos recursos e estruturas de saúde na capital, sinalizando problemas de gestão para vigilância em saúde e questões sanitárias advindas do esquema de regionalização da saúde no Amazonas ${ }^{22}$.

Conforme o estudo realizado por Vasconcelos et al. ${ }^{2}$ sobre a qualidade da água potável na Amazônia Legal, menos de 50\% dos municípios entre 2009 e 2013 executaram de forma concomitante a vigilância de registro e o controle de qualidade da água. Nesse período, $80,64 \%$ dos municípios do estado do Amazonas foram classificados como áreas altamente vulneráveis no que diz respeito às baixas pontuações nos indicadores de qualidade e abastecimento de água, a partir da análise de dados do Sisagua².

Ademais, o desempenho insatisfatório da vigilância em saúde em regiões de saúde no Amazonas, motivado por insuficiência de recursos humanos e financeiros, é agravado pela dificuldade de integração das ações e serviços devido às longas distâncias entre os municípios e a dependência do transporte fluvial precário ${ }^{23}$.

Os parâmetros básicos de qualidade analisados são considerados os critérios mínimos para que a água possa ser consumida pelo ser 
humano. No entanto, a partir dos resultados apresentados, observa-se que, além de ausentes, muitos parâmetros não estão em conformidade com os critérios estabelecidos pela legislação vigente ${ }^{4}$.

A quantidade de cloro residual na água na faixa ideal recomendada é uma das principais formas de desinfecção de água. Nas amostras verificadas para a microrregião de Manaus, observou-se oscilações importantes na concentração de cloro residual livre, sendo verificado, em 2020, um alto percentual na amostragem abaixo do limite inferior da faixa ideal recomendada para este parâmetro. Tais evidências merecem atenção, uma vez que, com baixo custo e grande eficiência em eliminar bactérias, a ausência ou inadequação desse parâmetro pode contribuir para a proliferação dos micro-organismos nas vias hídricas' ${ }^{1}$.

A fluoretação é uma das principais e mais importantes formas de prevenção coletiva no controle da cárie dentária, desde que os níveis na água estejam adequados, sendo que o excesso pode causar risco à saúde bucal por comprometer a dentição e a quantidade insuficiente não possibilita a prevenção como método populacional efetivo ${ }^{8}$.

Observa-se concentrações de flúor em todas as amostras analisadas nas microrregiões do interior do estado em 2018 e 2019, notificando-se ainda alta proporção de amostras em 2017 e 2020 fora da faixa adequada para este parâmetro químico. A ausência de dados para concentração de flúor em 2017 reflete a lacuna existente no controle desse parâmetro no Brasil e são compartilhados por outros estudos aplicados em diferentes regiões nacionais. De acordo com Frazão et al. ${ }^{24}$, o Brasil não oferece indicadores para monitorar longitudinalmente a fluoretação e nem visibilidade a todos os que têm direito à informação. Para tanto, a dosagem de fluoreto na água vem sendo monitorada tanto por instituições ligadas ao governo, denominadas de heterocontrole, quanto por companhias de saneamento e abastecimento hídrico que alimentam o sistema Vigifluor do Sisagua com o objetivo de assegurar a efetividade do uso de flúor em níveis adequados e diminuir a fluorose ${ }^{12,24}$.

Em 2020, mais de $98 \%$ das amostras coletadas no Amazonas apresentaram intensidade de coloração aparente na faixa recomendada pelas normativas vigentes. No entanto, para as microrregiões localizadas no interior, verificou-se uma tendência de queda na proporção de amostras com níveis de coloração adequados. De forma oposta, a microrregião de Manaus segue uma tendência de aumento na proporção de amostras classificadas na faixa recomendada para o parâmetro em questão. De acordo com a Organização Mundial da Saúde, a água de uso e consumo humano não deve ter coloração visível, sendo esta percepção associada a presença de matéria orgânica (ácidos húmicos e fúlvicos) e minerais, oriundos de impurezas naturais ou resíduos industriais ${ }^{25,26}$. A maioria dos indivíduos consegue perceber níveis de coloração na água acima de $15 \mathrm{uH}^{25}$. Altos níveis de coloração denotam uma grande propensão para geração de subprodutos indesejáveis nos processos de desinfecção da água ${ }^{26}$. As águas naturais apresentam intensidade de cor que variam entre 0 e $200 \mathrm{uH}$, sendo a cloração de águas com forte intensidade sujeita à formação de compostos cancerígenos, tais como trihalometanos ${ }^{26}$.
Apesar das oscilações, foram elevados os percentuais de amostras na faixa recomendada de turbidez. Este parâmetro é útil para sinalizar a dispersão de partículas químicas e biológicas em suspensão, tais como argila, lodos, precipitados químicos de ferro e manganês, restos de plantas e micro-organismos, sendo alvo para indicadores de eventos ambientais e poluição que comprometem a potabilidade da água ${ }^{27}$. 0 aumento da turbidez também pode ser provocado por falhas e perda de integridade na rede distribuição, tais como rompimentos de tubulações, ou por eventos biológicos, como a formação de biofilmes que propiciam o crescimento de patógenos como Legionella, Pseudomonas e micobactérias ${ }^{27}$. Assim, alcançar a baixa turbidez é um critério para garantia da segurança de potabilidade, sendo um indicativo para remoção de patógenos e partículas indesejáveis e efetividade dos processos de floculação, filtragem e desinfecção ${ }^{27}$.

A turbidez e a acidez da água têm relação com a composição química, sedimentos depositados e com o ambiente geológico em que foram formados, e são influenciados diretamente pelo local de coleta. As águas dos rios e igarapés da região central da Amazônia são quimicamente distintas entre si. O Rio Negro apresenta maior quantidade de substâncias orgânicas solúveis e maior acidez ( $\mathrm{pH}$ entre 4,0 e 5,0) devido a uma menor quantidade de minerais e substâncias fúlvidas e húmicas dissolvidas. De forma comparativa, as águas do rio Solimões, ou Rio Amazonas, como é denominado em algumas regiões, Amazonas, Madeira e Purus, classificadas como "água branca", apresentam-se turvas devido à quantidade de material em suspensão e sais dissolvidos como $\mathrm{Ca}^{2+}$ e $\mathrm{HCO}_{3}$, fazendo com que as águas sejam fracamente ácidas a neutras ( $\mathrm{pH}$ entre 6,0 e 7,0) e mais condutivas ${ }^{28,29}$.

É preocupante a alta proporção de amostras coletadas na microrregião de Manaus com valores de $\mathrm{pH}$ abaixo do recomendado. Além de afetar diretamente os consumidores, a água com valores de $\mathrm{pH}$ fora da faixa recomendada pode se tornar altamente corrosiva ou causar incrustações na rede de distribuição ${ }^{25,26}$.

A análise de parâmetros microbiológicos, embora seja utilizada como um indicador indireto/auxiliar da qualidade da água, monitora o desempenho dos processos de filtração, desinfecção e condições gerais dos sistemas de canalização e de distribuição da água do abastecimento público ou privado até o consumidor, evidenciando a falha na desinfecção, colonização e presença de biofilmes no sistema de distribuição desse recurso hídrico 5,20,21,22.

As tendências de aumento nas proporções de amostras ausentes para coliformes totais e E. coli são indicadores positivos para melhora da potabilidade da água distribuída nas microrregiões do interior do Amazonas. Os parâmetros microbiológicos da água relacionados a coliformes totais $e E$. coli demonstram a presença de contaminações bacteriológicas que podem ocasionar doenças diarreicas que causam mortalidade nas diferentes faixas etárias. Nos resultados, a tendência de diminuição desses parâmetros evidencia a melhoria do processo de controle dos órgãos fiscalizadores relacionados à coleta, ao transporte, ao armazenamento e a processos de obtenção deste recurso hídrico.

A ausência de informações precisas e padronizadas sobre a presença de bactérias heterotróficas no presente estudo é um fator 
preocupante, uma vez que esse parâmetro é considerado de suma importância para embasar conclusões sobre a qualidade microbiológica da água de consumo $0^{30}$, pois pode diagnosticar mudanças no padrão da contagem de colônias microbianas, e fornece uma indicação precoce de deterioração e integridade do sistema de abastecimento, além de detectar patógenos oportunistas importantes como Pseudomonas, Acinetobacter, Xanthomonas e Aeromonas, os quais não são identificados pelos demais parâmetros microbiológicos ${ }^{31}$.

Pesquisas na literatura vem apresentando dados sobre a ocorrência de fungos, bactérias heterotróficas, salmonela, $E$. coli e coliformes totais nas mais variadas fontes de água e em diferentes regiões do Brasil ${ }^{5,6,1,32}$. Não há como confirmar relação direta com o consumo hídrico uma vez que a morbimortalidade também pode estar associada à ineficiência da atenção básica e/ou assistência hospitalar do município ou região, no entanto a presença desses micro-organismos na água pode levar a óbito por meio da infecção de bactérias tolerantes a antibióticos e a outros antimicrobianos, além de patologias que causam vômitos, diarreia e outros comprometimentos gastrointestinais. Há ainda o risco de contaminação indireta, durante a cocção dos alimentos, higienização de mãos, de superfícies e dos alimentos ${ }^{14}$.

As pesquisas sobre águas originadas de rios, igarapés e poços no município de Manaus e no interior, Coari, Parintins e Humaitá, vêm sendo descritas como inapropriadas, com níveis inadequados dos parâmetros químicos e biológicos. Isso ressalta a importância da qualidade da água de consumo ofertada pelas empresas de abastecimento e saneamento público ${ }^{10,11,33}$.

Esses resultados vêm sendo corroborados por outras pesquisas em locais diferentes que demonstram a mesma preocupação relacionada a contaminações hídricas. Sabe-se que a vigilância da qualidade da água não é uma problemática exclusiva da Região Norte, uma vez que pesquisas em outros estados demonstram que o saneamento básico é um entrave nos países em desenvolvimento.

Espera-se que, a partir dessas informações, possa-se contribuir com o incentivo de pesquisas futuras sobre vigilância à saúde, cumprimento da legislação e políticas públicas existentes e melhoria das tecnologias de tratamento de água no Brasil, visando a superação de riscos à saúde ocasionados pela inadequação da água de consumo humano.

Dentre as limitações do estudo, não foram realizadas verificações de amostragens da vigilância da qualidade da água considerando as faixas populacionais estimadas para o quantitativo mínimo de amostras dos parâmetros cloro residual livre, turbidez, coliformes totais e $E$. coli, conforme preconizado pela Diretriz Nacional do Plano de Amostragem da Vigilância da Qualidade da Água para o Consumo Humano ${ }^{34}$. Outra limitação foi o fato de não haver informações quanto ao pareamento na amostragem no banco de dados disponibilizado pelo Sisagua, no que diz respeito ao número de parâmetros avaliados em uma mesma amostra. A análise de múltiplos parâmetros por amostra permitiria abordagens mais detalhadas, tais como a análise de componentes principais, para se determinar perfis físico-químicos ${ }^{35} \mathrm{e}$ microbiológicos para se discriminar as águas de abastecimento.

\section{CONCLUSÕES}

A análise de dados do Sisagua aponta que as microrregiões localizadas no interior do Amazonas apresentam menor proporção de municípios com dados cadastrados para vigilância de parâmetros básicos de qualidade da água. As amostras de água obtidas na microrregião de Manaus possuem baixo teor de cloro residual livre, maior teor de fluoreto e valores mais elevados de coloração aparente e turbidez, em comparação com as amostras coletadas nas microrregiões do interior.

Mostram-se preocupantes o alto percentual de amostras coletadas na microrregião de Manaus classificadas fora da faixa de $\mathrm{pH}$ recomendada pelas normativas em vigência, bem como a elevada proporção de amostras obtidas nas microrregiões do interior com concentrações de fluoreto inadequadas, incluindo a tendência de piora do parâmetro de cor aparente da água distribuída nestas localidades. Tais achados compõem um conjunto de dados que sinalizam a necessidade de melhorias no controle dos parâmetros químicos e físicos que orientem adequadamente os processos de captação, tratamento e distribuição de água.

Entretanto, são notórias as tendências de melhorias nos parâmetros de qualidade para cor aparente nas amostras de água obtidas na microrregião de Manaus, e para os parâmetros de cloro residual livre, coliformes totais e $E$. coli nas amostras coletadas nas microrregiões do interior do Amazonas.

A análise dos parâmetros de qualidade da água no Sisagua do Amazonas ressalta a necessidade de melhorias na gestão, vigilância e monitoramento dos resultados das amostras incluídas no Sisagua, no que se refere ao olhar atento para as ações de análise e de fiscalização da qualidade da água no estado do Amazonas, levando em consideração ainda as especificidades sociodemográficas e limitações de infraestrutura, recursos humanos e entraves geográficos da região, cujos resultados demonstraram haver importantes distinções entre as microrregiões analisadas.

\section{REFERÊNCIAS}

1. Damke T, Pasini F. A importância da potabilidade da água no saneamento básico para a promoção da saúde pública no Brasil. Rev Teccen. 2020;13(1):8-15. https://doi.org/10.21727/teccen.v13i1.2200
2. Vasconcelos $\mathrm{CH}$, Andrade RC, Bonfim CV, Resende RMS, Queiroz FB, Daniel MHB et al. Surveillance of the drinking water quality din the Legal Amazon: analysis of vulnerable areas. Cad Saúde Coletiva. 2016;24(1):14-20. https://doi.org/10.1590/1414-462X201500040142 
3. Fortes ACC, Barrocas PRG, Kligerman DC. A vigilância da qualidade da água e o papel da informação na garantia do acesso. Saúde Debate. 2019;43(spe3):20-34. https://doi.org/10.1590/0103-11042019S302

4. Ministério da Saúde (BR). Portaria de consolidação № 5 , de 28 de setembro de 2017. Consolidação das normas sobre as ações e os serviços de saúde do Sistema Único de Saúde. Diário Oficial União. 29 set 2017.

5. Norete DN, Correia QB, São José JFB. Qualidade da água utilizada em quiosques de praia. Rev Ambient Água. 2018;13(2):1-8. https://doi.org/10.4136/ambi-agua.2003

6. Castro RS, Cruvinel VRN, Oliveira JLM. Correlação entre qualidade da água e ocorrência de diarreia e hepatite $A$ no Distrito Federal/Brasil. Saúde Debate. 2019;43(spe3):8-19. https://doi.org/10.1590/0103-11042019S301

7. Guedes AF, Tavares LN, Marques MNN, Moura SP, Souza MNA. Tratamento da água na prevenção de doenças de veiculação hídrica. J Med Health Prom. 2017;2(1):452-61.

8. Motter J, Moyses ST, França BHS, Carvalho ML, Moysés SJ. Análise da concentração de flúor na água em Curitiba, Brasil: comparação entre técnicas. Rev Panam Salud Publica. 2011;29(2):120-5.

9. Paula DLM, Lima ACM, Vinagre MVA, Pontes AN. Sanitation on fluvial passenger ships in amazônia: an analysis of risks to the environment and to health through fuzzy logic. Eng Sanit e Ambient. 2019;24(2):283-94. https://doi.org/10.1590/S1413-41522019150122

10. Andrade FS, Silva AM, Aride PHR, Oliveira AT. Análise físico-química e da microbiota da água do lago Macurany, Parintins, Amazonas. Biota Amaz. 2016;6(2):132-4. https://doi.org/10.18561/2179-5746/ biotaamazonia.v6n2p132-134

11. Costa TACR, Oliveira BOS, Valente KS. Avaliação da qualidade de águas de poços cacimbas e rasos no município de Humaitá, AM. Rev Educ. 2018;20(1):157-72.

12. Rebelo MAB, Freitas YNL, Bandeira RHL, Quadros LN, Gome ASC, Gomes AC et al. A fluoretação das águas de abastecimento público: uma análise a partir do princípio da equidade. Vigil Sanit Debate. 2020;8(4):93-100. https: / /doi.org/10.22239/2317-269x.01491

13. Uhr JGZ, Schmechel M, Uhr DDAP. Relação entre saneamento básico no Brasil e saúde da população sob a ótica das internações hospitalares por doenças de veiculação hídrica. Rev Adm Contab Econ Fundace. 2016;7(2):1-16.

14. Nunes-Carvalho MC, Jayme MMA, Carmo FL, Pyrrho AS, Leite SGF, Araujo FV. Influence of different sources of contamination on the microbiological quality of lettuce in the Teresópolis region, RJ, Brazil. Eng Sanit Ambient. 2020;25(2):229-35. https://doi.org/10.1590/S1413-41522020144815

15. Queiroz ACL, Cardoso LSM, Silva SCF, Heller L, Cairncross S. Programa nacional de vigilância em saúde ambiental relacionada à qualidade da água para consumo humano (Vigiagua): lacunas entre a formulação do programa e sua implantação na instância municipal. Saude Soc. 2012;21(2):465-78. https://doi.org/10.1590/S0104-12902012000200019

16. Fundação Nacional de Saúde - Funasa. Vigilância ambiental em saúde. Brasília: Fundação Nacional de Saúde; 2002.

17. Oliveira A, Magalhães TB, Mata RN, Santos FSG, Oliveira DC, Carvalho JLB et al. Sistema de informação de vigilância da qualidade da água para consumo humano (Sisagua): características, evolução e aplicabilidade. Epidemiol Serv Saúde. 2019;28(1):1-17. https://doi.org/10.5123/S1679-49742019000100024

18. Instituto Brasileiro de Geografia e Estatística - IBGE. IBGE cidades. Rio de Janeiro: Instituto Brasileiro de Geografia e Estatística; 2021[acesso 16 ago 2021]. Disponível em: https://cidades.ibge.gov.br/

19. Instituto Brasileiro de Geografia e Estatística - IBGE. Malha municipal. Rio de Janeiro: Instituto Brasileiro de Geografia e Estatística; 2020 [acesso 12 ago 2021]. Disponível em: https://www.ibge.gov.br/geociencias/ organizacao-do-territorio/malhas-territoriais/15774malhas.html?=\&t=o-que-e

20. Ministério da Saúde (BR). Manual de procedimentos de entrada de dados do sistema de informação de vigilância de qualidade da água para consumo humano (Sisagua). Brasília: Ministério da Saúde; 2016[acesso 12 ago 2021]. Disponível em: http: //portalarquivos2.saude.gov.br/ images/pdf/2016/agosto/08/Manual-de-procedimentos-deentrada-de-dados-do-Sisagua---Vigil--ncia.pdf

21. Doyle JD, Tunnicliff $B$, Kramer R, Kuehl R, Brickler SK. Instability of fecal coliform populations in waters and bottom sediments at recreational beaches in Arizona. Water Res. 1992;26(7):979-88. https://doi.org/10.1016/0043-1354(92)90205-I

22. Garnelo L, Sousa ABL, Silva CDO. Health regionalization in Amazonas: progress and challenges. Cienc Saúde Coletiva. 2017;22(4):1225-34. https://doi.org/10.1590/1413-81232017224.27082016

23. Albuquerque AC, Cesse EAP, Felisberto E, Samico IC, Frias PG. Avaliação de desempenho da regionalização da vigilância em saúde em seis Regiões de Saúde brasileiras. Cad Saúde Pública. 2019;35(suppl.2):1-16. https://doi.org/10.1590/0102-311X00065218

24. Frazão P, Ely HC, Noro LRA, Pinheiro HHC, Cury JA. O modelo de vigilância da água e a divulgação de indicadores de concentração de fluoreto. Saúde Debate. 2018;42(116):274-86. https://doi.org/10.1590/0103-1104201811622

25. World Health Organization - WHO. Water quality and health: review of turbidity: information for regulators and water suppliers. Geneva: World Health Organization; 2017[acesso 16 ago 2021]. Disponível em: https://apps.who.int/iris/handle/10665/254631

26. Ministério da Saúde (BR). Vigilância e controle da qualidade da água para consumo humano. Brasília: Ministério da Saúde; 2006[acesso 10 ago 2021]. Disponível em: https://bvsms.saude.gov.br/bvs/ publicacoes/vigilancia_controle_qualidade_agua.pdf 
27. World Health Organization - WHO. Guidelines for drinkingwater quality: fourth edition incorporating first addendum. Geneva: World Health Organization; 2017[acesso 16 ago 2021]. Disponível em: https://apps.who.int/iris/ handle/10665/254637

28. Queiroz MMA, Horbe AMC, Seyler P, Moura CAV. Hidroquímica do rio Solimões na região entre Manacapuru e Alvarães, Amazonas, Brasil. Acta Amaz. 2009;39(4):943-52. https: / / doi.org/10.1590/\$0044-59672009000400022

29. Gomes AT, Cunha HB. Caracterização hidroquímica nas águas dos rios Negro e Solimões da região próxima da cidade de Manaus, Am. In: Anais da $20^{a}$ Jornada de Iniciação Científica Pibic INPA CNPq-Fapeam; Manaus, Brasil. Manaus: Fundação de Amparo à Pesquisa do Estado do Amazônia; 2011.

30. Ministério da Saúde (BR). Diretriz nacional do plano de amostragem da vigilância da qualidade da água para consumo humano. Brasília: Ministério da Saúde; 2016[acesso 11 abr 2021]. Disponível em: http://bvsms. saude.gov.br/bvs/publicacoes/diretriz_nacional_agua_ consumo_humano.pdf

31. Freire RC, Lima RDA. Bactérias heterotróficas na rede de distribuição de água potável no município de Olinda-PE e sua importância para a saúde pública. J Manag Prim Heal Care. 2013;3(2):91-5. https://doi.org/10.14295/jmphc.v3i2.144

32. Specian AM, Specian AMP, Nascimento AL, Col RDC, Daros VSMG, Mattos EC et al. Ocorrência de bactérias heterotróficas, coliformes totais e Escherichia coli em amostras de água de abastecimento público de dois municípios do estado de São Paulo. Bol Epidemol Paul. 2021;18(205):13-22.

33. Nunes SS, Soares FMP, Reis JS. Bacteriological analysis of domestic water reservoirs of Coari, Amazonas. Rev Saúde Biol. 2015;10(3):9-14.

34. Ministério da Saúde (BR). Diretriz nacional do plano de amostragem da vigilância da qualidade da água para consumo humano. Brasília: Ministério da Saúde; 2016[acesso 12 ago 2021]. Disponível em: http: //bvsms. saude.gov.br/bvs/publicacoes/diretriz_nacional_plano_ amostragem_agua.pdf

35. Dovidauskas S, Okada IA, Iha MH, Cavallini AG, Okada MM, Briganti RC et al. Mapeamento da qualidade da água de abastecimento público no nordeste do estado de São Paulo (Brasil). Vigil Sanit Debat. 2017;5(2):53-63. https://doi.org/10.22239/2317-269x.00862

Contribuição dos Autores

Lopes AF, Mendes AP, Yamaguchi KKL - Concepção, planejamento (desenho do estudo), análise, interpretação dos dados e redação do trabalho. Santana ABC - Concepção, planejamento (desenho do estudo), aquisição, análise, interpretação dos dados e redação do trabalho. Todos os autores aprovaram a versão final do trabalho.

Os autores informam não haver qualquer potencial conflito de interesse com pares e instituições, políticos ou financeiros deste estudo.

Licença CC BY-NC atribuição não comercial. Com essa licença é permitido acessar, baixar (download), copiar, imprimir, compartilhar, reutilizar e distribuir os artigos, desde que para uso não comercial e com a citação da fonte, conferindo os devidos créditos de autoria e menção à Visa em Debate. Nesses casos, nenhuma permissão é necessária por parte dos autores ou dos editores. 